\title{
The Outcomes of Superior Cavopulmonary Connection Operation: a Single Center Experience
}

Alwaleed Al-Dairy'1, MD; Maziar Gholampour Dehaki ${ }^{1}$, MD; Gholamreza Omrani', MD; Ali Sadeghpour ${ }^{1}$, MD; Amir Hossein Jalali ${ }^{1}$, MD; Reza Sadat Afjehi ${ }^{1}$, MD; Mohammad Mahdavi ${ }^{2}$, MD; Mahmood Salesi ${ }^{3}$, PhD

\section{Abstract}

Introduction: The superior cavopulmonary connection operation is one of the stages of the palliative surgical management for patients with functionally single ventricle. After surviving this stage, the patients are potential candidates for the final palliative procedure: the Fontan operation.

Objectives: This study aimed to analyze the outcomes of superior cavopulmonary connection operations in our center and to identify factors affecting the survival and the progression to Fontan stage.

Methods: The outcomes of 161 patients were retrospectively analyzed after undergoing superior cavopulmonary connection operation in our center between 2005 and 2015.

Results: The early mortality rate was $2.5 \%$. Five (3.1\%) patients underwent takedown of the superior cavopulmonary connection.
The rate of exclusion from the Fontan stage was $8.3 \%$. Statistical analysis revealed that elevated mean pulmonary artery pressure preoperatively and the prior palliation with pulmonary artery banding were risk factors for both early mortality and takedown; however, the age, the morphology of the single ventricle and the type of operation were not considered risk factors.

Conclusion: The superior cavopulmonary connection operation can be performed with low rate mortality and morbidity; however, the elevated mean pulmonary artery pressure preoperatively and the prior pulmonary artery banding are associated with poor outcomes.

Keywords: Fontan Procedure. Heart Bypass, Right. Heart Ventricles/pathology. Heart Defects, Congenital/surgery.

\begin{tabular}{ll}
\hline Abbreviations, acronyms \& symbols \\
\hline CPB & $=$ Cardiopulmonary bypass \\
CTA & $=$ Computed tomographic angiography \\
LV & $=$ Left ventricle \\
mPAP & $=$ Mean pulmonary artery pressure \\
PAB & $=$ Pulmonary artery banding \\
PAP & $=$ Pulmonary artery pressure \\
RV & $=$ Right ventricle \\
SCPC & $=$ Superior cavopulmonary connection \\
TAPVC & $=$ Total anomalous pulmonary venous connection \\
TCPC & $=$ Total cavopulmonary connection \\
TTE & $=$ Transthoracic echocardiography
\end{tabular}

'Department of Cardiovascular Surgery, Division of Congenital Cardiac Surgery of Rajaie Cardiovascular Medical and Research Center, Iran University of Medical Sciences, Tehran, Iran.

2Department of Pediatric Cardiology, Rajaie Cardiovascular Medical and Research Center, Iran University of Medical Sciences, Tehran, Iran.

${ }^{3}$ Atherosclerosis Research Center, Baqiyatallah University of Medical Sciences, Tehran, Iran.

This study was carried out at Rajaie Cardiovascular Medical and Research Center, Iran University of Medical Sciences, Tehran, Iran.

\section{INTRODUCTION}

The superior cavopulmonary connection (SCPC) operation represents one of the stages for the surgical palliation in patients with functionally univentricular hearts. This operation may or may not be preceded by a first stage palliation; however, it is well known that this operation results in more efficient oxygenation than the systemic pulmonary shunt with the advantage of avoiding the volume or pressure overload of the single ventricle $e^{[1]}$. There are two basic surgical techniques for creating a cavopulmonary connection, the bidirectional superior cavopulmonary anastomosis (bidirectional Glenn operation) and the Hemi-Fontan operation. In those patients who have an interruption of the inferior vena cava with azygous or hemiazygous continuation, a bilateral superior cavopulmonary connection operation is performed with all the systemic venous

No conflict of interest.

No financial support.

Correspondence Address:

Gholamreza Omrani

Department of Cardiovascular Surgery

Rajaie Cardiovascular Medical and Research Center, Tehran 0098, Iran

E-mail: gromrani@gmail.com

Article received on February $3^{\text {rd }}, 2017$. Article accepted on May $18^{\text {th }}, 2017$. 
return is directed to the pulmonary circulation except for the portal venous return, this operation is called "Kawashima operation"[2]. However, the development of pulmonary arteriovenous malformations and pulmonary arteriovenous fistulae remains a potential complication following Kawashima operation ${ }^{[2-6]}$. The patients who survive the SCPC operation are potential candidates for the final palliative procedure: the Fontan operation ${ }^{[7]}$.

This study aimed to analyze the outcomes of SCPC operations in our center and to identify factors affecting the survival and the progression to Fontan stage.

\section{METHODS}

\section{Study Protocol and Population}

Between 2005 and 2015, 161 patients with single ventricle physiology due to variable congenital heart defects underwent SCPC in our center, Rajaie Cardiovascular Medical and Research Center. In a retrospective study, the outcomes of these patients concerning the clinical conditions, the survival rates, and the progression to the final palliative stage were analyzed (Fontan stage). Baseline demographics, preoperative, and intraoperative data were collected from their charts. This study protocol was approved by the local ethics committee in our institution.

\section{Patients Follow-Up}

The patients were regularly followed up in the outpatient clinic (1 week and 1 month after surgery, then every 3 months), with complete physical examination and transthoracic echocardiography (TTE). The follow-up data were obtained

Table 1. The underlying congenital heart defects.

\begin{tabular}{|c|c|}
\hline Congenital heart defect & Values $^{\mathrm{a}}$ \\
\hline TA & $60(37.3 \%)$ \\
\hline PS or PA with or without VSD & $23(14.3 \%)$ \\
\hline TGA & $22(13.7 \%)$ \\
\hline CC-TGA & $11(6.8 \%)$ \\
\hline DILV & $10(6.2 \%)$ \\
\hline Mitral atresia & $9(5.6 \%)$ \\
\hline DORV or DOLV with upstairs downstairs ventricles & $8(5 \%)$ \\
\hline Heterotaxy syndrome & $7(4.3 \%)$ \\
\hline Unbalanced CAVSD & $6(3.7 \%)$ \\
\hline Large multiple VSDs & $5(3.1 \%)$ \\
\hline \multicolumn{2}{|c|}{$\begin{array}{l}\text { aAll values are presented as number (\%). } \\
\text { CAVSD=complete atrioventricular septal defect; cc-TGA=congenitally } \\
\text { corrected transposition of great arteries; DILV= double inlet lef } \\
\text { ventricle; DOLV=double outlet left ventricle; DORV=double } \\
\text { outlet right ventricle; PA=pulmonary atresia; PS=pulmonary } \\
\text { stenosis; TA=tricuspid atresia; TGA=transposition of great arteries } \\
\text { VSD=ventricular septal defect }\end{array}$} \\
\hline
\end{tabular}

from chart review, with special attention to survival and the completeness of the final palliative stage.

\section{Diagnostic Evaluations}

The main diagnostic device was the TTE for both preoperative diagnosis and postoperative follow-up. For further anatomical evaluation and especially for measuring the mean pulmonary artery pressure (mPAP), cardiac catheterization was performed preoperatively in 113 (70\%) patients. For those patients who had not undergone cardiac catheterization, the PAP was measured intraoperatively. Additionally, computed tomographic angiography (CTA) was performed in 90 (55.9\%) patients.

\section{Statistical Analysis}

Continuous variable were presented as mean \pm SD or median (interquartile range) as appropriate. Qualitative variables were presented as frequency and percentage. Mann Whitney $U$ test was used to compare two groups' means and $P$ value < 0.05 was considered statistically significant. All statistical analyses were performed using SPSS 20 for windows (IBM Inc., Somers, NY, USA).

\section{RESULTS}

\section{Baseline Characteristics}

Median age at SCPC operation was $5 \pm 4.9$ years (range 9 months to 24.5 years), and $54 \%$ of the patients were male (87 patients). Mean mPAP preoperatively was $13 \pm 3.6 \mathrm{mmHg}$ (range 7-27 mmHg). The most common congenital heart defect in our patients was tricuspid atresia (60 patients, 37.3\%). The underlying congenital heart defects are summarized in Table 1.

\section{Intra- and Post-Operative Outcomes}

Primary SCPC defined as SCPC operation without any previous palliative operations was performed in 61 (37.9\%) patients, and secondary SCPC (with prior palliation) in the remainder. The prior palliative operations included systemic pulmonary shunt in 63 (39.1\%) patients, pulmonary artery banding (PAB) in 25 (15.5\%), PAB with atrial septectomy in 5 (3.1\%), systemic pulmonary shunt with atrial septectomy in 5 (3.1\%), and atrial septectomy in two (1.3\%) (Figure 1).

The predominant ventricle was with left ventricle (LV) morphology in $118(73.3 \%)$ patients, with right ventricle (RV) morphology in 41 (25.5\%), and with intermediate morphology in two (1.2\%).

The type of the SCPC operation was right SCPC in 128 (79.5\%) patients, left SCPC in seven (4.3\%), bilateral SCPC in 18 (11.2\%), hemi-Fontan in two (1.2\%), and Kawashima operation in six (3.8\%) (Figure 2). The operation was carried out using cardiopulmonary bypass (CPB) except for 22 patients in whom right SCPC was performed without CPB (13.7\% of the cohort). The azygous (or the hemiazygous) vein was ligated and divided in 96 (59.6\%) patients. Previous systemic pulmonary shunt (if existed) was taken down in 75\% of the cases, without any effect on the outcomes. Concomitant operations at the time of SCPC included: repair of pulmonary artery branches $(n=8)$, atrioventricular valve 


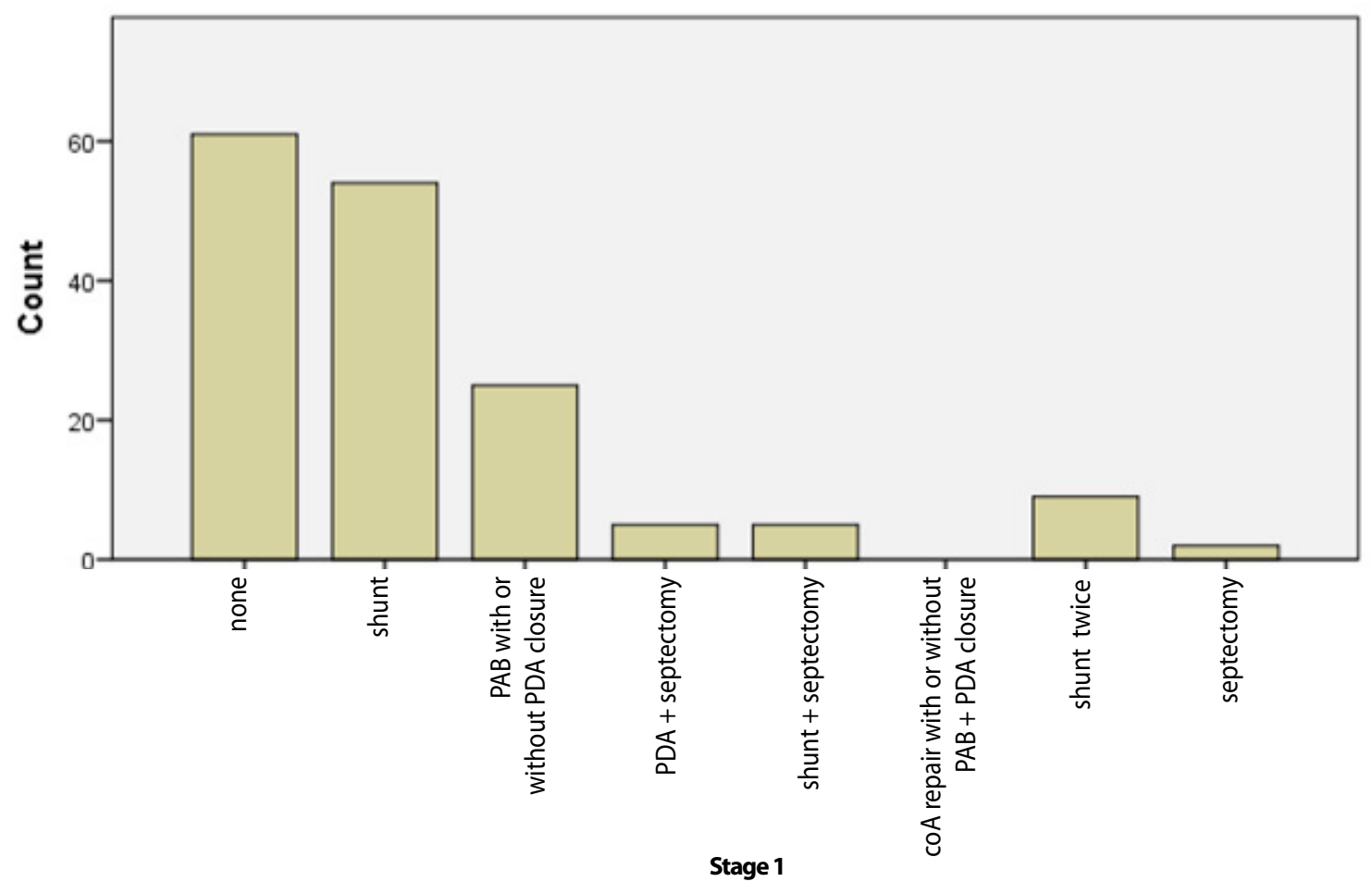

Fig. 1 - The palliative operations performed as first stage palliation. "Count" is expressed as absolute numbers. COA=Coarctation of the aorta; $P A B=$ pulmonary artery banding; PDA=patent ductus arteriosus

repair ( $n=3)$, total anomalous pulmonary venous connection (TAPVC) repair $(n=2)$, and atrial septectomy $(n=2)$.

Four $(2.5 \%)$ patients died in the hospital due to pulmonary infection (two patients), failure of the SCPC which was taken down (one patient), and low cardiac output syndrome with disseminated intra vascular coagulation (one patient). The characteristics of these patients are summarized in Table 2. Mean mPAP in this group of patients (in-hospital mortality) was $20 \pm 1.63 \mathrm{mmHg}$, which was significantly higher than that in the survived patients $(12.85 \pm 3.44 \mathrm{mmHg}),(P=0.001)$. Two patients underwent takedown of the SCPC on the same day of operation; one of them died in the hospital and the other was alive after a 2-year follow-up period. Twelve (7.5\%) patients suffered from prolonged pleural effusion (> 14 days), with three of them having chylothorax.

\section{Follow-Up}

Median follow-up time after the SCPC operation was 3.1 1.9 years (range 6 months to 10 years). Two (1.27\%) late deaths occurred during the follow-up period, both of them due to heart failure. The rate of freedom from mortality in the followup period was $96.27 \%$. Thirty-seven (23.57\%) patients underwent total cavopulmonary connection (TCPC), and 99 others (63\%) are waiting for TCPC. Thirteen (8.3\%) patients were not candidates for TCPC due to high PAP (7 patients of whom three patients underwent takedown of the SCPC), poor development of pulmonary arteries (three patients), ventricular dysfunction (two patients), and viral hepatitis (one patient). No patient (especially from those who underwent Kawashima operations) developed pulmonary arteriovenous fistulas during the period of this study.

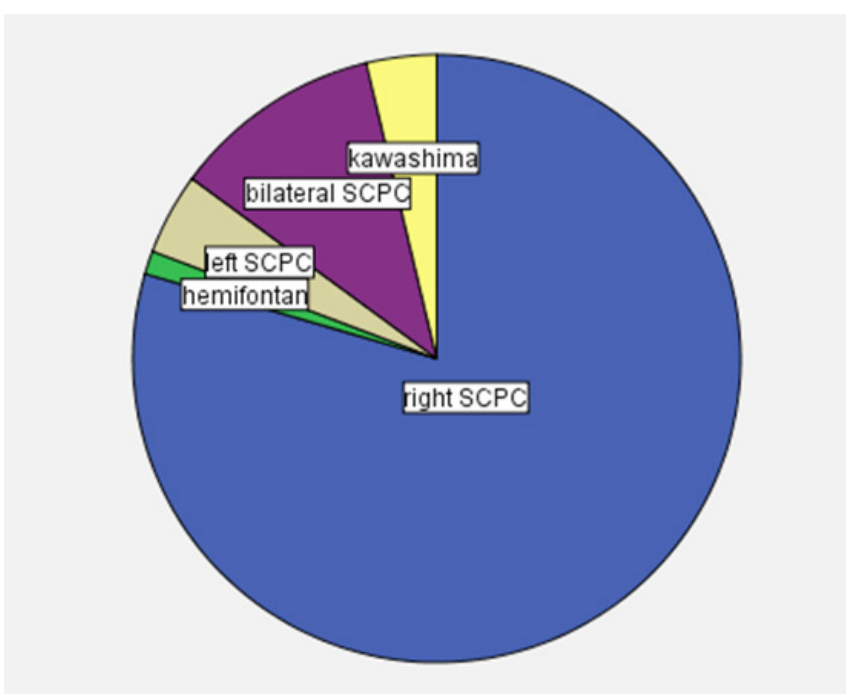

Fig. 2 - Type of superior cavopulmonary connection. SCPC=superior cavopulmonary connection. Right SCPC in $79.5 \%$ of the patients, left SCPC in 4.3\%, bilateral SCPC in 11.2\%, hemi-Fontan in $1.2 \%$, and Kawashima operation in $3.8 \%$. 
Table 2. Characteristics of the in-hospital mortality patients.

\begin{tabular}{c|c|c|c|c|c|c}
\hline Patient & Age $^{\mathbf{a}}$ & Diagnosis & Prior palliation & Type of SCPC & mPAPb & Associated procedures \\
\hline 1 & 3 & PS without VSD & Shunt & Right SCPC without pump & 18 & None \\
\hline 2 & 6 & Unbalanced CAVSD & PAB & Right SCPC with pump & 20 & None \\
\hline 3 & 1.5 & TA+PS & None & Right SCPC with pump & 20 & PA branch repair \\
\hline 4 & 1 & Heterotaxy syndrome & None & Right SCPC with pump & 22 & TAPVC repair \\
\hline
\end{tabular}

aage at operation in years, ${ }^{b}$ mean pulmonary artery pressure in $\mathrm{mmHg}$ preoperatively, ${ }^{\mathrm{C}}$ pulmonary artery branch repair $\mathrm{CAVSD}=$ complete atrioventricular septal defect; $\mathrm{mPAP}=$ mean pulmonary artery pressure; $\mathrm{PA}=$ pulmonary atresia; $\mathrm{PAB}=$ pulmonary artery banding; $P S=$ pulmonary stenosis; SCPC=superior cavopulmonary connection; VSD=ventricular septal defect; $T A=$ tricuspid atresia;

TAPVC=total anomalous pulmonary venous connection

\section{Takedown of the SCPC}

Five patients underwent takedown of the SCPC (two on the same day of SCPC operation of whom one died, and three during follow-up). The common denominator among these patients was the prior palliation with PAB. Furthermore, their mean mPAP preoperatively $(17.4 \pm 3.29 \mathrm{mmHg})$ was significantly elevated when compared with that of the other patients $(12.87 \pm 3.5$ $\mathrm{mmHg}),(P=0.01)$. All the patients who survived the takedown of the SCPC were excluded from the completeness of TCPC due to elevated mPAP. The characteristics of the patients who underwent takedown of the SCPC are summarized in Table 3.

\section{DISCUSSION}

The early mortality rate after SCPC operation in our study was $2.5 \%$. Five (3.1\%) patients underwent takedown of the SCPC of whom two at the same operation day and three later during the follow-up period. The rate of exclusion from the TCPC was $8.3 \%$. Statistical analysis revealed that elevated mPAP preoperatively and the prior palliation with $\mathrm{PAB}$ were risk factors for both early mortality and takedown of the SCPC; however, the age, the morphology of the single ventricle, and the type of SCPC were not considered risk factors. The diagnosis of large multiple ventricular septal defects or the upstairs downstairs ventricles with double outlet right ventricle or double outlet left ventricle was associated with poor outcomes but due to the small number of patients a statistically significant correlation could not be found.

Preoperative MPAP has been reported as a risk factor for death after the Glenn procedure ${ }^{[8]}$, and mortality in those receiving pulmonary artery banding was high ${ }^{[9]}$, and these findings were compatible with ours. From our perspective it is essential to protect the pulmonary vascularity in patients with single ventricle and unrestricted pulmonary blood flow since that the PAP importantly affects the results of the surgical palliation in these patients.

There is no consensus regarding the ideal time for performing the SCPC in patients with single ventricle ${ }^{[10]}$. Age did not seem to influence the outcomes; however, we recommend surgery as earlier as possible, although other logistic factors such as the availability of specialized centers and physicians may affect the trend to perform the SCPC earlier.

The elimination of an accessory pulmonary blood flow (prior systemic pulmonary shunt) at the time of SCPC operation did not affect the outcomes. On the other hand, some studies suggested that this may be advantageous on a long-term basis ${ }^{[11]}$.

Pulmonary arteriovenous malformations and pulmonary arteriovenous fistulas did not develop during the follow-up period in this study in patients who underwent Kawashima operation. In one study, this complication arose in 58\% of the patients in a median follow-up period of 5 years after Kawashima operation ${ }^{[6]}$.

Table 3. Characteristics of the takedown patients.

\begin{tabular}{c|c|c|c|c|c|c}
\hline Patient & Age $^{\mathbf{a}}$ & Diagnosis & Prior palliation & mPAPb & Time of takedown & Follow-up \\
\hline 1 & 1.25 & Large multiple VSDs & PAB & 12 & The same operation day & 2 years \\
\hline 2 & 6 & Unbalanced CAVSD & PAB & 20 & The same operation day & Died in the hospital \\
\hline 3 & 3 & DORV upstairs/downstairs ventricles & PAB & 20 & After 3.5 years & 9 years \\
\hline 4 & 1 & DORV upstairs/downstairs ventricles & PAB & 17 & After 3 years & 9 years \\
\hline 5 & 2 & DOLV upstairs/downstairs ventricles & PAB & 18 & After 3 years & 7 years \\
\hline
\end{tabular}

aage at SCPC operation in years, ${ }^{b}$ mean pulmonary artery pressure in $\mathrm{mmHg}$ preoperatively.

$\mathrm{CAVSD}=$ complete atrioventricular septal defect; $\mathrm{DORV}=$ double outlet right ventricle; mPAP=mean pulmonary artery pressure;

$\mathrm{PA}=$ pulmonary atresia; $\mathrm{PAB}=$ pulmonary artery banding; $\mathrm{PS}=$ pulmonary stenosis; $\mathrm{SCPC}=$ superior cavopulmonary connection;

VSD=ventricular septal defect; TA=tricuspid atresia; TAPVC=total anomalous pulmonary venous connection

\section{6}




\section{Limitation}

The retrospective nature of this study is one of its main limitations, and the short follow-up period in some patients was another considerable one.

\section{CONCLUSION}

The SCPC operation is an essential stage for the surgical palliation in patients with univentricular heart and can be performed with a low rate of mortality and morbidity; however, the elevated mPAP and the prior palliation by PAB remain an important risk factors for poor outcomes.

\section{Authors' roles \& responsibilities}

AAD Substantial contributions to the conception or design of the work; final approval of the version to be published

MGD Final approval of the version to be published

GO Final approval of the version to be published

AS Drafting the work or revising it critically for important intellectual content; final approval of the version to be published

AHJ Drafting the work or revising it critically for important intellectual content; final approval of the version to be published

RSA Drafting the work or revising it critically for important intellectual content; final approval of the version to be published

MM Final approval of the version to be published

MS Acquisition, analysis, or interpretation of data for the work; final approval of the version to be published

\section{REFERENCES}

1. Tanoue Y, Kado H, Boku N, Tatewaki H, Nakano T, Fukae K, et al. Three hundred and thirty-three experiences with the bidirectional Glenn procedure in a single institute. Interact Cardiovasc Thorac Surg. 2007;6(1):97-101.

2. Kawashima Y, Kitamura S, Matsuda H, Shimazaki Y, Nakano S, Hirose H. Total cavopulmonary shunt operation in complex cardiac anomalies: a new operation. JThorac Cardiovasc Surg. 1984;87(1):74-81.

3. Baruah SD, Mishra S, Marwah A, Sharma R. Hepatoazygos venous shunt for Fontan completion after Kawashima operation. Ann Pediatr Cardiol. 2016;9(3):254-7.

4. Kavarana MN, Jones JA, Stroud RE, Bradley SM, Ikonomidis JS, Mukherjee R. Pulmonary arteriovenous malformations after the superior cavopulmonary shunt: mechanisms and clinical implications. Expert Rev Cardiovasc Ther. 2014;12(6):703-13.

5. Srivastava D, Preminger T, Lock JE, Mandell V, Keane JF, Mayer JE Jr, et al. Hepatic venous blood and the development of pulmonary arteriovenous malformations in congenital heart disease. Circulation. 1995;92(5):1217-22.

6. Brown JW, Ruzmetov M, Vijay P, Rodefeld MD, Turrentine MW. Pulmonary arteriovenous malformations in children after the Kawashima operation. Ann Thorac Surg. 2005;80(5):1592-6.

7. Mendoza A, Albert L, Ruiz E, Boni L, Ramos V, Velasco JM, et al. Fontan operation. Hemodynamic factors associated with postoperative outcomes. Rev Esp Cardiol. 2012;65(4):356-62.

8. Petrucci O, Khoury PR, Manning PB, Eghtesady P. Outcomes of the bidirectional Glenn procedure in patients less than 3 months of age. J Thorac Cardiovasc Surg. 2010;139(3):562-8.

9. Alsoufi B, Manlhiot C, Ehrlich A, Oster M, Kogon B, Mahle WT, et al. Results of palliation with an initial pulmonary artery band in patients with single ventricle associated with unrestricted pulmonary blood flow. Thorac Cardiovasc Surg. 2015;149(1):213-20.

10. Cnota JF, Allen KR, Colan S, Covitz W, Graham EM, Hehir DA, et al. Superior cavopulmonary anastomosis timing and outcomes in infants with single ventricle. J Thorac Cardiovasc Surg. 2013;145(5):1288-96.

11. Mainwaring RD, Lamberti JJ, Uzark K, Spicer RL, Cocalis MW, Moore JW. Effect of accessory pulmonary blood flow on survival after the bidirectional Glenn procedure. Circulation. 1999;100(19 Suppl):II151-6. 